\title{
CRITIQUE OF FUNCTIONALISM IN THE WORKS OF ANTHONY GIDDENS AND NORBERT ELIAS: A COMPARISON
}

\author{
Aleksejs Šṇitṇikovs \\ Riga Technical University, Latvia
}

\begin{abstract}
The purpose of the paper is to assess the arguments of the critique of functionalism by Anthony Giddens and Norbert Elias. After being subject to severe criticism, terminology of functionalism is still a part of the lexicon of social scientists nowadays. Functionalist reasoning and concepts of functionalism are used in sociology, political science and economics, even though often without full awareness of its theoretical implications. Recent revival of interest in the works by Elias is connected with the search for a new theoretical and methodological foundation of sociology but his views on functionalism have remained largely unexplored. For the analysis presented in this paper, main theoretical works by Giddens and major works by Elias have been used. Positions of the authors have been analysed with respect to main concepts and principles of functionalism, such as function, needs, internalization of values, consensus, equilibrium, and the notions of power and individual. The study shows that while Giddens strived to reject functionalism and the concept of social function altogether, in the figurational approach developed by Elias it is possible to use some of the concepts of functionalism without necessarily accepting its controversial tenets.
\end{abstract}

Keywords: equilibrium, function, functionalism, individual, interdependence, needs, power, society, values.

\section{Introduction}

Norbert Elias and Anthony Giddens developed distinctive approaches to sociological problems. Elias, a first-generation sociologist, according to his own characterization (Elias, 2009a), advocated the study of societies in historical perspective, while viewing humans in the plural, as a network of interdependent individuals, or figurations. The approach he originated is known as processual and figurational. Giddens in the late 1970's proposed structuration theory, in which he tried to synthesize the developments in modern social theory, in particular structural and interpretative schools, while attempting to provide a solution to 'structure' and 'agency' quandary. Elias and Giddens knew each other, as they were colleagues at the University of Leicester where they were working in the 1960 's. Both were critical to functionalism but in different ways. 
The works by Giddens represent one of the current grand syntheses in sociological theory but it is doubtful whether it has achieved its intended result, for the field is still characterised by divergent and conflicting approaches. In the past two decades there has been a revival of the interest in the works by Elias, which is evidenced, for example, by the growing number of publications which apply his approach (Gabriel, Mennell, 2011) and founding of the journal "Human Figurations" (2012) dedicated to the development of processual-figurational approach. The works of Elias are seen as providing inspiration and guidance for building a new theoretical foundation of sociology and for its future development (Dunning \& Hughes, 2013).

Critique of functionalism is a distinct element of Giddens's theoretical writings. In the secondary literature on Elias it is pointed out that he has been critical to functionalism but it is often unnoticed that in fact he used the concepts associated with functionalism in a way which was consistent with his processualfigurational approach. The purpose of this paper is to provide a comparative analysis of the critical views of Giddens and Elias on the concepts and principles of functionalism as contained in the major works of these authors, identifying similarities and differences in their positions on the matter. On the examples from the works of Elias it shows that concepts which are used in functionalism, such as function, needs and equilibrium, can be applied in social analysis outside of the functionalist paradigm.

\section{The concept of "harmonious whole" and value consensus}

Both Giddens and Elias were critical to the tendency contained in functionalism that societies are seen as self-contained entities with clear boundaries thought of by analogy with biological organism. They rejected the image of societies as "harmonious wholes" - as more or less stable systems composed of functionally interdependent parts. In normative functionalism, this conception presupposes moral consensus based on shared cultural values, socialization of individuals into this common culture, which ensures the internalization of these values (Parsons \& Shils, 1962). The social order establishes the fit between the shared moral consensus and the motivation of individuals. For Giddens this view is not acceptable, it is 'notoriously suspect' and 'at best partial' view of society (Giddens, 2015: 124); the social systems are not so unified (Giddens, 1993: 130). Within the framework of this concept it is difficult to explain the existence of dissentions and divergent interpretations of the common value system. Norms and values are not just internalized. Norms can be an object of negotiation or conditional, pragmatic acceptance. Also, this conception is not useful for the explanation of conflicts between groups based on the clash of interests, as in class struggle (Ibid). The theorem "value consensus - 
norm - internalized need-dispositions" turns the human actors into "cultural dopes' (Giddens, 1979: 71, 112). It leaves little room for reflexive, purposeful action of the individuals.

For Elias, the presupposition that the social system is a harmonious whole also is not acceptable as a starting point of analysis or theory. For Elias, such a conception is an abstracted, idealized picture of $20^{\text {th }}$-century democratic statesociety. Elias also criticized functionalism for implicitly involving value judgement in considering something as functional or dysfunctional. Functional is something which is "good" for sustaining the integrity of the "whole". "The inappropriateness of the evaluation is due to the fact that they tend unintentionally - to use the terms for those tasks performed by one part of the society which are 'good' for the 'whole', because they contribute to the preservation and integrity of the existing social system" (Elias, 1978: 77). The concept of a 'whole' as applied to society is misleading and metaphysical (Elias, 1978: 72). It is not useful for empirical research of social relationships.

Elias criticized Talcott Parsons's functionalism for creating a picture of society in the state of rest and ignoring the historical variability of social forms. The social system normally exists in a state of equilibrium, but when it is upset by a violation of norms, the social system strives to regain the balance. People obey the same norms and values through common socialization and are more or less equal (Elias, 2001: 467). Elias rejected this view because it is biased by focusing on the contemporary society, which is relatively more egalitarian and integrated than the societies in the past. The notion that society is an integrated system where people share the same norms and values is ahistorical. Such concepts are not realistic as models of pre-modern societies with "a high percentage of slaves or unfree subjects, or of feudal or hierarchical states - that is, societies in which not even the same laws, let alone the same norms and values, apply to all people" (Elias, 2001: 467-468).

\section{The concept of needs}

Giddens criticized functionalism for using the concept of the underlying society's needs as an explanation for social phenomena. In functionalism, the needs are those prerequisites which must be met for the society to survive and the human action is explained as being directed, often unconsciously, by the imperative to satisfy those needs, such as integration, adaptation to the physical environment, allocation of resources and formulation of common goals. Thus apparently 'irrational' social practices such as a 'rain dance' in tribal societies are explained by the need to sustain the integration of the group. Giddens criticizes this concept of the need as applied to the social system. He argues that functionalism has been following too closely the analogy with the organic 
systems, which can be said to have the interest in their own survival. Giddens claims the following: "Social systems, unlike organisms, do not have any need or interest in their own survival" (Giddens, 2015: 110). The idea that the social system has needs or reasons of its own is rejected by Giddens: "societies or social systems have no reasons or needs whatsoever" (Giddens, 1979: 211). As soon as it is posited that the social systems do not have needs or reasons, the reference to needs cannot serve as an explanation of the existence of practice: "Not even the most deeply sedimented institutional features of societies come about because those societies need them to do so" (Giddens, 1979: 113). The explanation of the existence of the institution should refer to the historical conditions of its appearance.

If one holds the functionalist position about the latent needs and functions, then purposes of the individuals lose their relevance to the social action, which is unacceptable to Giddens. Human actors, through rationalization and reflexive monitoring of action, convert their wishes into purposes and intentions, the expected outcomes which they actively seek to achieve (Giddens, 2015: 125). Giddens argues that 'needs' are conscious to the individuals. In course of their practice, they employ knowledge about the effects of their actions to meet those needs. The only usage of the concept of needs he admits is 'counterfactual' - that is, these 'needs' are not the property of the system, but serve as a methodological device for the researcher (Giddens, 1978: 114).

In the works of Elias there is a different treatment of the concept of needs. It is manifest in his concept of survival unit. Survival units are empirically identifiable collectivities such as tribes, city-states, empires, territorial, or nationstates and they have an interest in securing their survival. In fact, what constitutes them is the interest in maintaining the capacity to defend themselves or attack other survival units (Elias, 1991). It cannot be deduced from his works that social needs are wholly unknown to the social actors but the degree of their awareness can vary, especially when knowledge of the needs in a more established system is compared to cognizance of new demands, which arise in the process of transformations of the figuration.

Elias employs the concept of needs in explaining the genesis of the naval profession. But the reference to needs alone, as Elias points out, is not sufficient (Elias, 1950: 292). A new occupation is a manifestation of a new social function, which emerges in order to satisfy new human needs, which arise in conjunction with the development of technologies: "Human needs become differentiated and specific only in conjunction with specialized human techniques; these on their part emerge and crystallize into occupations only in view of potential and actual human needs" (Elias, 1950: 291-292). In his analysis the concepts of function and needs do not have the primacy; they are linked to the concepts of relationships and interdependence, so that the former are understood in conjunction with the 
latter. A new occupation is not created by one individual, it is the outcome of the change of the situation in the "whole community': "It is, in essence, a process of trial and error in which people attempt to match occupational techniques or institutions and human needs" (Elias, 1950: 292). The process of emergence and formalization of a new social function is usually accompanied by social tensions or conflicts among the groups occupying the particular social field which is followed by adjustments, compromises, trials and errors and finally accommodation between them, and institutionalization of the profession. This involves "people struggling, often in vain, to adjust their inherited institutional framework with all its incongruities to what they feel to be their own needs..." (Elias, 1950: 293). The naval profession in Europe emerged after the discoveries of the new lands on the other side of the Atlantic, which drew into competitive struggle England, Spain, Portugal, the Netherlands and France. That created the need for combination of competencies of the seamen and military men: "The new departure in maritime warfare created the need for people who in a new specialized form were seamen and military men at the same time" (Elias, 1950: 296).

In "The Civilizing Process" Elias explores the formation of the institution of tax collection based on the case of medieval France, in course of the Hundred Years' War. Initially the king's powers to collect taxes were very limited. It was not an established norm that the king had the right to raise taxes regularly. That was done on ad-hoc basis and such a right was given only for one year. It was opposed and disputed by the subjects of the realm, especially by the towns. But in the course of the war the need for regular taxation and the corresponding taxcollecting institution was recognized and finally, after resolution of conflicts among the involved social groups, in particular, the king, nobility and the nascent bourgeoisie, it became permanent. Elias writes on the problem the following: "No single person created taxes or the taxation monopoly; individual, nor series of individuals throughout the century in which this institution was slowly formed ${ }^{1}$, worked towards this goal by any deliberate plan" (Elias, 2001: 348). Taxation was brought about as an outcome of the conflict among these various parties over resources and authority and then more consciously and deliberately this political instrument was given the form of a permanent institution.

\section{Equilibrium, balance and causal loops}

It is characteristic of functionalism that social systems tend to be seen as selfregulating, maintaining the equilibrium between its component parts (Parsons \& Shils, 1962). This idea serves as an explanatory device because the behaviour of

\footnotetext{
${ }^{1}$ The fourteenth century (Author).
} 
social subsystems are judged as functional or dysfunctional depending on their contribution to maintaining the overall system equilibrium. The explanation involves identification of causal loops. The system part has to be 'functional' to the system and has to adapt its behaviour accordingly, otherwise it will be 'negatively selected'. The behaviour of the unit of social action is readjusted through the feedback loop - if the consequences of the action are found to be positive, or functional, for the system maintenance, then it will be positively reinforced. As Stinchcombe puts it: if a selective causal connection between $\mathrm{H}$ [homeostatic variable] and S [structure or behaviour] exists, such that S's are selected or reinforced if they maintain $\mathrm{H}$, then S's found in that situation will be more likely to be functional for maintaining H (Stinchcombe, 1968:88). In that sense the functionalists say that the cause of the behaviour is, indirectly, its consequence. The consequence or end which tends to be maintained functions indirectly as a cause of the behaviour or structure to be explained (Ibid).

Giddens admits that in the social systems there are homeostatic processes, which are similar to those in mechanical or biological systems (Giddens, 1979: 79). Unfortunately, he provides only a cursory treatment of such 'blind' homeostatic processes. One example that he mentions is a causal loop starting from material deprivation, leading to poor schooling, then to a low level of employment, which in turn leads back to material deprivation (Giddens, 1979: 79; 1986: 289). But he asserts that social action involves self-consciousness and reflexivity, and these are more important than mere processes of self-regulation. Human agents are knowledgeable of the conditions of their actions, even though they may not fully comprehend all their consequences. Thus even the pupils involved in the negative causal loop mentioned above (the school 'lads') are not unaware of their situation and their prospective life-chances (Giddens, 1986: 293). Moreover, these negative causal loops can be recognized as such and acted upon by the governmental agency in order to break the vicious circle.

Giddens is sceptical towards functionalists' description of self-regulating processes in social systems because it ascribes teleology to the social system instead of treating the human agents as purposeful. He argues that there is no such entity as 'structural explanation' in social sciences, for all explanations should contain reference both to purposeful, reasoning individuals and structural constraints (Giddens, 1986: 179).

It can be demonstrated, though, that Giddens does not completely escape the functionalist logic in his structuration theory. It is implied in his notions of ontological security and routine. Thus he explains much of social conduct by reference to the need to sustain the conditions of trust, or ontological security: “... there is a generalized motivational commitment to the integration of habitual practices across time and space" (Giddens, 1986: 64). He derives the need to sustain the conditions of trust from the need to control the 'diffuse anxiety', which 
is "the most generalized motivational origin of human conduct" (Giddens, 1986: 54). The importance of routines and routinization are derived from these basic socio-psychological needs. "The concept of routinization, as grounded in practical consciousness, is vital to the theory of structuration" (Giddens, 1986: 60). This logic is not different from what Parsons and Shils wrote with respect of cultural norms: “. . . there is a tendency of systems of action to build up and maintain levels of consistency... The basis of this tendency rests in the functional need for order which underlies any action system, which entails the need for integration and its cultural components" (Parsons \& Shils, 1962: 175). Without stability and complementarity of expectations, according to Parsons and Shils, the ego and alter cannot relate to each other in a mutually gratifying way. The difference is that for Parsons and Shils the homeostatic variable is order but for Giddens it is the ontological security, which, after all, are similar concepts.

Elias warned against the use of biological analogies in the analysis of social processes, which is implicit in the model of homeostatic processes. Elias objected the view of society as a closed entity. He stressed that making account of the social processes requires investigation of the processes 'inside' the society as well as the external relationships with other societies. Moreover, the boundaries of the polity may be porous or fluid, which makes it difficult to ascertain what is 'inside' and what is 'outside' of the society.

The concepts of balance and equilibrium are used in Elias's works, but these are characterizations of empirical social processes and do not imply a social system's teleology. On the contrary, he emphasized that the outcomes of the unplanned processes of social development and of figurational dynamics are not pre-determined. The concept of balance in his works often is used in association with the concept of power. Thus, there may be the balance of power among various social actors - between the states, the rulers and the ruled, employers and workers or between the sexes (Elias, 1978, 2001, 2009b).

The concepts of balance and equilibrium often appear in his major work "The Civilizing Process". There the balance of power is established between the emerging states, among the competing princes, between the king and the subjects and among the various groups making up the differentiating society. According to Elias's theory of the civilizing processes, the growing differentiation, the division of labour results not simply in greater solidarity, but in ambivalent relationships: people not only increasingly become dependent on each other but also become competitors for the same opportunities. The growing interdependence results both in solidarity and hostility. Writing about the figuration of social forces at the end of the middle ages, he points out that the social groups "oscillate between the desire to win major advantages over their social opponents and their fear of ruining the whole social apparatus, on the functioning of which their actual social existence depends" (Elias, 2001: 319). He 
considers that this is characteristic of societies with the developed division of functions: "different parts of society hold each other roughly in balance in terms of social strength" (Elias, 2001: 322). Then Elias makes a generalization saying that the equilibrium of tensions is characteristic of all societies: "Equilibrium in the field of tensions making up every society always arises in differentiated human networks through the collaboration and collision of a large number of groups and classes" (Elias, 2001: 323).

The concept of equilibrium comes up in his discussion of the genesis of the institution of taxation. "Taxation", writes Elias, "like any other institution, is a product of social interweaving. It arises (...) from the conflicts of the various social groups and interests..." (Elias, 2001:248). He points out that the particular administrative organ for state finances (Chambre des Aides) during the Hundred Years' War appeared, then under the pressure of social groups disappeared and then reappeared again. Summarizing this process, he notes: "Like a system of forces that has not yet reached equilibrium, society swayed back and forth between the various poles in the struggle of power" (Elias, 2001: 351) ${ }^{2}$.

\section{The term 'function'}

In his book "Central Problems of Social Theory" Giddens declared that he wanted to 'ban' the term 'function' from the social sciences. One reason, as pointed out above, is that the term 'function' presupposes that a social structure meets presumed needs of the social system, the existence of which Giddens rejects: "The term 'function' implies some sort of teleological quality that social systems are presumed to have: social items or activities are held to exist because they meet functional needs" (Giddens, 1986: 295). Another reason is that the use of the term 'function' creates an illusion of explanation of the phenomena, whereas in fact the term does not explain anything. Pointing out to the fit between a social practice and the presumed need of the system does not serve as an explanation. To say that the function of education system is to allocate the individuals to positions in the division of labour in the society is not to provide explanation or clarification. It remains to be explained to what extent the allocation of individuals to different jobs are intended or unintended consequences of the operation of educational system (Giddens, 1986: 297). The acceptable forms of explanation would involve references to the purposes of the actors and the unintended consequences of their actions. An explanation of the social phenomena must explicate the relationships between the elements which comprise the causal loop in the particular case (Giddens, 1979: 113).

\footnotetext{
${ }^{2}$ It can be noted that the ideas of power struggle and 'punctuated equilibrium' are used in the explanation of the genesis of institutions in modern institutional analysis (Thelen, 2009).
} 
It could be said that Elias criticized the use of the concepts of function in structural functionalism but not the concept as such, because he used it quite often himself. His critique was directed on the static, ahistorical character of this concept, as it was used by functionalists: "Immutability is treated as the normal condition of society. It is embedded in such basic sociological concepts as 'social structure' and 'social function"' (Elias, 1978: 152). He was also critical to the idea of social "function" as a task which is performed by individuals or a group within a "harmonious "whole"" (Elias, 1978: 78).

In "The Civilizing Process" he used the term 'function' in connection with the notion of the division of labour. So he speaks of progressive division of functions and concomitant economic development - urbanization, monetization and industrialization. In this process more and more people become functionally dependent on each other, as they perform the specialized tasks within the "network of differentiated social functions" (Elias, 2001: 434).

Another use of the term 'function' refers to the position of the king. In course of the process of state formation, the position of the ruler gradually turned into a permanent function. Elias argues that when the interdependence of social groups and regions is slight, there is no much need in the central ruler except his role as a military leader and, occasionally, a judge (Elias, 2015: 315). The need for the central ruler becomes greater with the progressive division of labour and growth of complexity of society because that demands that more resources are devoted to coordination of activities (Elias, 2001: 314). As a result of subsequent institutional changes, the king becomes the 'functionary' of the society.

In one of his later essays Elias attempted to enumerate "process universals" the common structural features of all survival units, ranging from small bands of people to large modern states (Elias, 2009c). These are sets of "elementary functions" which the groups have to fulfil in order to survive. The first one is the economic function - the provision of food and other material necessities. The second one is the function of the control of violence within the group and also in relation to other groups. The third one is the function of production and transmission of knowledge or means of orientation - on human group can survive without it. The fourth one is the function of self-restraint; humans have to learn self-restraint in order to live in the society, as they lack inborn self-restraint. He stressed that this is an empirically verifiable model for the study of social processes, which can be tested and corrected (Elias 2009c).

In his book "What is Sociology?" Elias introduces a relational concept of function. One group can be a "function" to another because of their interdependence. They need not be enclosed into a common "social system", each performing complementary tasks or "functions" for each other. The rivalry between groups also make them interdependent, but in another way: in order to survive, these groups have to check each other's actions and screen each other's 
Aleksejs S̆nitnikovs. Critique of Functionalism in the Works of Anthony Giddens and Norbert Elias: a Comparison

intentions (Elias, 1978: 77). The antagonistic groups have to prepare to possible open conflict, or, as the case may be, to undertake preparations for war. In this context, the criteria of having a "function" is the interdependence of individuals or groups in the struggle for survival.

\section{The concept of power}

Another point of Giddens's criticism of Parsons's functionalism is a peripheral role of power that he assigns in his theory. Power, according to Parsons, is secondary to norms (Giddens, 1993: 26). Parsons defines power as a generalized legitimate capacity of the group in the societal system to implement collective goals. Legitimacy thus is implied in the definition of power. For Parsons, the main characteristic of power is its function - it serves the need of attaining the collectively valuable goals by taking binding decisions. Through the electoral process the politicians are given the mandate, the 'grant of power', which can be revoked in the next elections. If the trust and confidence in politicians are strengthened, the power is enhanced; if the trust diminishes, then power deflation occurs and it is necessary to bolster it with force and coercion.

Giddens considers that Parsons overemphasized the significance of legitimation and consensus over the use of power in the social systems and generally underplayed the role of power in social affairs. Power, in his view, does not necessarily presuppose conflict, and here he agrees with Parsons. Power can be enhanced in the whole system and it is not just a zero-sum game. But it tends to involve contestation, when it is applied in social interaction in the form of domination. There may be disagreements over the goals as expressed in the conflicts of interests of different groups and competition and struggle over the incumbency of the power positions. Power can be defined generally as a transformative capacity of the social agents. It is a valuable and scarce asset, and thus invokes conflicts of interests. Power, in Giddens's view, can be based on trust and confidence, but also on deception and manipulation: "If the use of power rests upon 'trust' and 'confidence', as Parsons emphasizes, it also frequently rests upon deceit and hypocrisy" (Giddens, 2015: 341). The real sources of power may reside outside of official politics and it is a mistake, therefore, to take the electoral politics at the face value, as Parsons does.

Elias likewise considers power to be a basic, fundamental feature of social relations. But he criticized the sociological theories of power contemporary to him, including functionalism, by treating power as a sort of thing or substance rather than a structural aspect of social relationships. The concept of power in functionalism figures as a variable in a static system, while the more adequate concept of power, in Elias's view, is that it emerges in the processes of social interweaving (Elias, 1978: 116). Power should be conceptualized as a 
characteristic of relationship and thus 'power ratio' or 'power balance', in Elias's view, are more preferable terms. He derives power from the concept of interdependence. In the system of interdependencies, some actors have greater relative strength while others are more dependent (Elias, 1978: 79). For example, in the absolutist state, the king and various social groups are interdependent, but the king, by virtue of his central position, is more powerful.

\section{Conceptualization of the individual}

Another point of Giddens's criticism is that functionalism, in his view, treats intentional action unsatisfactorily: the structure and function dominate the subject, functionalism dispenses with the active individual (Giddens, 2015: 117). The concept of internalization of norms and values found in Parsons's works make the individuals passive and conformist. This is not quite well compatible with the notion that the social life is actively constituted (Giddens, 1993: 26). Individuals do not figure in functionalism as creative, reflexive, skillful performers in interaction (Giddens, 1993: 165). Functionalism, in Giddens's view, lacks the theory of action, despite its contrary claim. Parsons's actors, according to Giddens, "are not capable, knowledgeable agents" (Giddens, 1978: 254). The concept of the agent that Giddens puts forwards presupposes that human actors know a great deal about the working of society. Individuals are not merely motivated, they have conscious intentions. In action and interaction, individuals use rules and resources, whereby reproducing social structures, but they also deliberately alter them, making interventions in the social world and producing new social structures. The individuals have the transformative capacity through employing the resources and using the rules, making them at the same time the object of transformation - that, in short, is the message of his structuration theory.

Elias's critique of Parsons's functionalism in this respect is different. He criticizes this version of functionalism for improper conceptualization of individuals and society as two separate entities which exist in a state of rest. In the view of Elias, this approach is unsatisfactory in that it ignores the historicalprocessual aspect of the problem. Parsons's functionalism operates with a 'closed' concept of the ego - "homo clausus" - the image of the lonely individuals isolated from the social context. The result of this is a sharp dichotomy between personality and the social system. His approach to the problem involved the study of individualization as a historical process evolving over many centuries. In course of historical development, the salience of individualistic consciousness grows, but the identification with the collective 'we' is decreasing (Elias, 1991).

According to the approach that he advocated, the object of sociological reflection should be people-in-society, people in plural, or 'homines aperti' (Perulli, 2011). His concept of figuration presupposes that individuals are 
interdependent and therefore the actions and plans of the individuals cannot be seen as entirely freely chosen; these are explained by taking into account the compelling forces which individuals or groups exert upon each other by reason of their interdependence, be that enmity or cooperation.

\section{Conclusions}

In their works Giddens and Elias point to weaknesses and problematic assumptions of functionalism. Uncritical application of concepts and propositions found in functionalism, such as value consensus, individuals' motivation as derived from internalization of values, the concept of society's needs, power as a function of the collectivity, may lead to a one-sided view of social reality. Functionalism makes societies seem more stable than they really are. Explanation of social structures and behaviour by reference to the function they perform for the whole social system is not sufficient and may be misleading; it should be complemented or corrected by historical explanation, the study of combined effects of intended and unintended consequences of actions. Giddens even suggests to put the ban on the use of the term 'function' in social sciences. This proposal, however, is excessive.

In the works of Elias the term 'function' is used in a way which is different from functionalism's 'hidden' teleology. One can talk about 'functions' in the systems of the division of labour on the scale of organization or wider social units, the nation-state or international systems of cooperation. One can talk of the functions of the 'attack-and-defence unit' - the survival unit.

The social scientist can make use of a more abstract, relational concept of function, as applied in the analysis of interdependencies, the human figurations, which might include both cooperative and inimical relationships. The concept of social needs can be understood as an emergent phenomenon of figurational dynamics - the changes in human interdependencies. These needs, or figurational pressures, can be recognized by the social actors to various degrees. Likewise, the concepts of balance and equilibrium can be detached from the pre-determined teleology of the social system. These can be used as descriptions of certain states in social figurations.

\section{References}

Dunning, E. \& Hughes, J. (2013). Norbert Elias and Modern Sociology. London: Bloomsbury. Elias, N. (1950). Studies in the Genesis of the Naval Profession. The British Journal of Sociology, Vol. 1, No. 4, 291-309.

Elias, N. (1978). What is Sociology? New York: Columbia University Press.

Elias, N. (1991). The Society of Individuals. Oxford: Blackwell.

Elias, N. (2001). The Civilizing Process. Oxford: Blackwell. 
Elias, N. (2009a). A diagnosis of present-day sociology. In: Essays III. On Sociology and the Humanities. Collected Works, Vol. 16 (pp. 99-106). Dublin: University College Dublin Press.

Elias, N. (2009b). The changing balance of power between the sexes - a process-sociological study: the example of the ancient Roman state. In: Essays III. On Sociology and the Humanities, Collected Works, Vol. 16 (pp. 240-265). Dublin: University College Dublin Press.

Elias, N. (2009c). The retreat of sociologists into the present. In: Essays III. On Sociology and the Humanities. Collected Works, Vol. 16 (pp. 107-126). Dublin: University College Dublin Press.

Gabriel, N. \& Mennell, S. (Eds.) (2011). Norbert Elias and Figurational Research: Processual Thinking in Sociology. Oxford: Wiley-Blackwell.

Giddens, A. (1979). Central Problems in Social Theory. Berkeley, Los Angeles: University of California Press.

Giddens, A. (1986). The Constitution of Society. Berkeley, Los Angeles: University of California Press.

Giddens, A. (1993). New Rules of Sociological Method. Second Edition. Cambridge: Polity Press.

Giddens, A. (2015). Studies in Social and Political Theory. Abingdon: Routledge.

Parsons, T. \& Shils, E. (1962). Values, Motives and Systems of Action. In: Parsons, T., Shils, E. (Eds.) Toward a General Theory of Action (pp. 47-247). New York: Harper Torchbooks.

Perulli, A. (2011). Beyond Dichotomous Thinking. The Society of Individuals. Cambio. Rivista sulle tranformazioni sociali. 1, 6-22.

Stinchcombe, A. (1968). Constructing Social Theories. New York: Harcourt, Bruce \& World, Inc.

Thelen, K. (2009). How Institutions Evolve: Insights from Comparative Historical Analysis. In: Mahoney, J., Rueschemeyer, D. (Eds.) Comparative Historical Analysis in Social Sciences (pp. 208-240). Cambridge: Cambridge University Press. 